\title{
CORRELATION OF OBESITY AND UNDERWEIGHT WITH FOETOMATERNAL OUTCOME- A PROSPECTIVE OBSERVATIONAL STUDY IN KIMS, KARAD
}

\author{
Manisha M. Laddad', Gauri Shinde², N. S. Khirsagar 3 , Sanjaykumar Patil 4 \\ ${ }_{1}^{1}$ Associate Professor, Department of Obstetrics and Gynaecology, Krishna Institute of Medical Sciences, Deemed University, Karad, \\ Maharashtra, India. \\ ${ }^{2}$ Assistant Professor, Department of Obstetrics and Gynaecology, Krishna Institute of Medical Sciences, Deemed University, Karad, \\ Maharashtra, India. \\ ${ }^{3}$ Professor, Department of Obstetrics and Gynaecology, Krishna Institute of Medical Sciences, Deemed University, Karad, Maharashtra, \\ India. \\ ${ }^{4}$ Professor, Department of Obstetrics and Gynaecology, Krishna Institute of Medical Sciences, Deemed University, Karad, Maharashtra, \\ India.
}

ABSTRACT

\section{BACKGROUND}

Obesity and being underweight in pregnancy are related to an increased risk of maternal and foetal morbidity, yet their prevalence is often unknown

The present study aimed to identify neighbourhoods with a higher than average prevalence or 'hot spots' of obesity and/or being underweight among mother and foetal outcome.

\section{MATERIALS AND METHODS}

This is a prospective, non-interventional, observational study on 1500 women (BMI between 20 and 30 were excluded). Women attending ANG OPD with singleton pregnancy at or before 14 weeks were included and BMI was calculated in early pregnancy. Their weight gain during pregnancy was noted. Any complications in the mother or perinate were noted.

\section{RESULTS}

Incidence of obesity in our institute was $19 \%$ and that of underweight was $21 \%$. Pre-eclampsia, gestational hypertension, gestational DM and antepartum haemorrhage all were more common among obese women, while anaemia and IUGR babies were more common in the underweight. Post-dated pregnancy, induction of labour, caesarean delivery and postpartum complications were more common in obese women. Foetal complications were also higher in obese patients.

\section{CONCLUSION}

Lower as well as higher pre-pregnancy BMI is an independent risk factor that is associated with increased morbidity and mortality in both the mother and the foetus.

\section{KEY WORDS}

Pregnancy, Obesity, Underweight, BMI, IUGR.

HOW TO CITE THIS ARTICLE: Laddad MM, Shinde G, Khirsagar NS, et al. Correlation of obesity and underweight with foetomaternal outcome- a prospective observational study in KIMS, Karad. J. Evolution Med. Dent. Sci. 2018;7(38):4208-4212, DOI: $10.14260 /$ jemds/2018/940

\section{BACKGROUND}

Overweight/ obesity in women of childbearing age is a serious public-health problem, especially in "developing" countries. In China, from 1992 to 2010, the prevalence of overweight or obesity in women aged 18 - 44 years increased from $16.8 \%$ to $26.4 \%$ and from $3.1 \%$ to $9.0 \%$, respectively.[1] Worryingly, these estimates of prevalence are higher in "developed" nations.

'Financial or Other Competing Interest': None.

Submission 07-08-2018, Peer Review 01-09-2018,

Acceptance 06-09-2018, Published 17-09-2018.

Corresponding Author:

Dr. Manisha M. Laddad

Associate Professor

Department of Obstetrics and Gynaecology,

Shri Sai Maternity Clinic,

72/A Block,

Vithal Housing Society, Malkapur,

Karad-415110, District-Satara

Maharashtra, India.

E-mail: drmanishald@gmail.com

DOI: $10.14260 / \mathrm{jemds} / 2018 / 940$

\section{(c) (1) $(9)$}

In the UK, the prevalence of maternal obesity has more than doubled from $7.6 \%$ to $15.6 \%$ from 1989 to 2007 , respectively. Obesity is attaining the status of global epidemic worldwide. Overall, in 2014 about $13 \%$ of the world's adult populations (11\% of men and $15 \%$ of women) were obese. In 2014, more than 1.9 billion adults 18 years and above were overweight. Of these, over 600 million were obese.[1,2] According to National Family Health Survey (NFHS),[2] the percentage of married women (15 - 49 years) who are overweight or obese increased from $11 \%$ (NFHS 2) to $15 \%$ (NFHS 3). Undernutrition is more prevalent in rural areas, whereas obesity is three times higher in urban area.

India is unique, as it suffers from a dual burden of obesity and malnutrition. More than one-third (36\%) women have BMI lower than 18.5. In India, a higher number of malnourished women reside in Chhattisgarh, Bihar and Jharkhand, whereas most of the obese women are from Punjab, Delhi and Kerala.[3]

The World Health Organisation (WHO) categorises a BMI equal or greater than 25 as 'overweight,' equal or greater than 30 as 'obese' and equal than or less than 18.5 as 'underweight.' [3] 
Obesity during pregnancy carries a higher risk $(1.32$ times) of morbidity and mortality for both mother and the foetus. On the other hand, underweight is associated with IUGR and anaemia, and PIH. Weight gain during pregnancy has a recommended range throughout 40 weeks of pregnancy. If the weight gain is more or less than the proposed, it is associated with an adverse outcome for both the mother and the baby.[4]

\section{MATERIALS AND METHODS}

This study was conducted after receiving approval by the Ethics Committee of KIMS, DU, Karad. This was a prospective, observational study on 1500 pregnant underweight women with BMI less than 19.9 and obese women with BMI more than 30. At Krishna Institute of Medical Sciences, Karad, Maharashtra.

\section{Sample Size}

1500 .

As per study of Agarwal et al, incidence of IUGR in obese is $7.4 \%$ and in underweight it is $0 \%$. In underweight, incidence was assumed 3\%. Sample size was calculated by using the following formula-

$\mathrm{N}=(\mathrm{q} 1+\mathrm{p} 2 \mathrm{q} 2)(\mathrm{Z}-\mathrm{alfa} / 2+\mathrm{Z1}$-beta) square $\div(\mathrm{p} 2-\mathrm{p} 2)$

This calculation revealed to study minimum sample size in 591 in obese and for underweight comes 591 with 95\% confidence and $95 \%$ power. In the present study, we enrolled 816 underweight and 684 obese.

\section{Inclusion Criteria}

Singleton pregnancy at or before 14 weeks of gestational age (before any significant impact of weight gain).

\section{Exclusion Criteria}

- Women with BMI 20 - 29.9.

- Multiple pregnancies.

- Major structural anomaly.

- Medical complications, such as diabetes and hypertension.

\section{BMI was calculated, and women were categorised into 5} groups

1. Group A, Underweight $<19.9 \mathrm{~kg} / \mathrm{m}^{2}$;

2. Group B, Normal $=20-24.9 \mathrm{~kg} / \mathrm{m}^{2}$ (excluded);

3. Group C, Overweight $=25-29.9 \mathrm{~kg} / \mathrm{m}^{2}$ (excluded);

4. Group D, Obese $=30-34.9 \mathrm{~kg} / \mathrm{m}^{2}$;

5. Group E, Morbidly Obese $>35 \mathrm{~kg} / \mathrm{m}^{2}$ (no woman was in this group).

In both groups, weight gain was noted according to Institute of Medicine (IOM) ${ }^{[5]}$ criteria on regular basis till delivery along with the complications and outcome. The outcomes of labour and delivery were compared between both groups. Descriptive statistics were calculated for all study variables. Continuous variables were presented as the mean and standard deviation, while categorical data were calculated as percentage. Bivariate analysis was done to examine the association between pre-pregnancy BMI and foetomaternal outcomes.

\section{Statistical Analysis}

The data collected were analysed statistically using SPSS version 21.0 software. The variables were then assessed for their prognostic significance. Chi-square test/ Fisher's exact test was used as the test of significance. A p-value of $<0.05$ was considered significant and $p<0.001$ was considered highly significant. A value of $\mathrm{p}<0.05$ was considered statistically significant. All statistical analyses were performed using SPSS for windows version 20.

\section{RESULTS}

A total of 2600 women were enrolled in this study from Jan 2014 to Dec 2015. After applying inclusion and exclusion criteria, 1500 women were included in the study sample. Among these 1500 women, 684 were obese and 816 were underweight. There was not a single woman in the morbidly obese group.

Women who were obese before pregnancy had a mean age of 26 years. Obese women were mostly from Karad and Jakhinwadi area as compared to lean women with mean age of 21.25 years. Lean women were mostly from rural area nearby Karad who were working in farm.

Significant number of the women had recommended weight gain in both groups. In the obese group, $60.7 \%$ women had induced labour and $54.8 \%$ were delivered by caesarean section (Table 1).

Obese women suffered more complications such as gestational diabetes, gestational hypertension, pre-eclampsia, macrosomia, antepartum haemorrhage, etc. Birth weight and proportion of babies weighing over $3.5 \mathrm{~kg}$ to $4 \mathrm{~kg}$ increased in the obese group (Table 2).

\begin{tabular}{|c|c|c|c|}
\hline & $\begin{array}{c}\text { Obese N=684 } \\
\text { (\%) }\end{array}$ & $\begin{array}{c}\text { Underweight } \\
\text { N= 816 (\%) }\end{array}$ & P value \\
\hline \multicolumn{4}{|c|}{ Weight Gain } \\
\hline Below normal & $97(14.18)$ & $230(28.18)$ & 0.0001 \\
\hline Normal & $389(56.87)$ & $337(41.29)$ & 0.0001 \\
\hline Above normal & $198(28.94)$ & $249(30.51)$ & 0.398 \\
\hline \multicolumn{4}{|c|}{ Mode of Delivery } \\
\hline Vaginal & $303(44.29)$ & $585(71.69)$ & 0.00001 \\
\hline LSCS & $381(55.70)$ & $231(28.30)$ & 0.00001 \\
\hline \multicolumn{4}{|c|}{ Labour Process } \\
\hline Spontaneous & $312(45.61)$ & $686(84.07)$ & 0.00001 \\
\hline \multicolumn{5}{|c|}{$372(54.38)$} & $130(15.93)$ & 0.00001 \\
\hline Tabluced 1. Comparison of Weight Gain and Mode of Delivery \\
in Both Groups \\
\hline
\end{tabular}

\begin{tabular}{|c|c|c|c|}
\hline & $\begin{array}{c}\text { Obese } \\
\mathbf{N = 6 8 4}\end{array}$ & $\begin{array}{c}\text { Underweight } \\
\mathbf{N =} \mathbf{8 1 6}\end{array}$ & P value \\
\hline $\begin{array}{c}\text { Maternal } \\
\text { complication }\end{array}$ & & & \\
\hline GDM & 43 & 16 & 0.00001 \\
\hline Macrosomia & 46 & 10 & 0.00001 \\
\hline Pre-eclampsia & 198 & 104 & 0.00001 \\
\hline GHTN & 146 & 106 & 0.002 \\
\hline IUGR & 54 & 52 & 0.541 \\
\hline Anaemia & 56 & 88 & 0.008 \\
\hline APH & 58 & 42 & 0.042 \\
\hline Foetal weight & & & \\
\hline$<2 \mathrm{~kg}$ & $66(9.64 \%)$ & $72(8.8 \%)$ & 0.541 \\
\hline $2-3 \mathrm{~kg}$ & $198(28.94 \%)$ & $540(66.17 \%)$ & 0.00001 \\
\hline $3-4 \mathrm{~kg}$ & $346(50.58 \%)$ & $204(25.05 \%)$ & 0.00001 \\
\hline
\end{tabular}




\begin{tabular}{|c|c|c|c|}
\hline$>4 \mathrm{~kg}$ & $74(10.81 \%)$ & 0 & 0.00001 \\
\hline $\begin{array}{c}\text { Foetal } \\
\text { complications }\end{array}$ & 45 & 14 & 0.009 \\
\hline Still birth & 22 & 16 & 0.0468 \\
\hline $\begin{array}{c}\text { Early neonatal } \\
\text { death }\end{array}$ & $\begin{array}{l}\text { Table 2. Comparison of Maternal and Foetal complications } \\
\text { in both groups }\end{array}$ \\
\hline
\end{tabular}

An interesting observation was that a higher total weight gain in pregnancy led to more antenatal complications (Table 3).

Preterm as well as post-term delivery is more common in the obese women (Table 4). Anaemia was more prevalent in lean women, whereas postpartum complications such as PPH and infections were frequently seen in obese women.

\section{DISCUSSION}

Pregnancy is a valuable event in the life of a woman. During pregnancy, a woman often visits the antenatal clinics. Small and simple parameters like weight gain over the past visit is often ignored by the busy obstetricians. Ideal weight gain is an important factor for a good foetomaternal outcome. Obesity is emerging as an epidemic worldwide. We were surprised to see the incidence of obesity in the antenatal women as $17 \%$, not too far behind from that of the US, where it is $20 \%$ in some antenatal clinics.[6] Incidence of underweight was $18 \%$, almost similar to that of obesity.

\begin{tabular}{|c|c|c|c|}
\hline & $\begin{array}{c}\text { Below Normal } \\
\text { N= 94 }\end{array}$ & $\begin{array}{c}\text { Normal } \\
\text { N= 182 }\end{array}$ & $\begin{array}{c}\text { Above Normal } \\
\text { N= 272 }\end{array}$ \\
\hline GDM & $6(6.38)$ & $16(8.79)$ & $24(8.82)$ \\
\hline Macrosomia & $0(0 \%)$ & $18(9.89)$ & $36(13.23)$ \\
\hline Pre-eclampsia & $28(29.78)$ & $46(25.27)$ & $102(37.5)$ \\
\hline GHTN & $24(25.53)$ & $40(21.97)$ & $68(25.00)$ \\
\hline IUGR & $15(15.95)$ & $28(15.38)$ & $22(8.08)$ \\
\hline APH & $19(20.21)$ & $34(18.68)$ & $20(7.35)$ \\
\hline \multicolumn{3}{|c|}{ Table 3. Effect of Maternal Weight Gain on Maternal } \\
Complications \\
\hline
\end{tabular}

Although, pregnancy complications in obese women are well documented, the evidence in relation to problems of underweight is less clear.[7] In this study, we have compared both the extremes of BMI with foetomaternal outcome.

In 2009, IOM put forth new guidelines regarding the gestational weight gain in relation to BMI.[5] The pregnancy and gestational weight gain, whether excessive or inadequate, are associated with a poor foetomaternal outcome.

The women in our study were mostly 23 years old in the underweight group and 29 years old in the obese group. They usually had unplanned pregnancy and low awareness about nutrition and its impact on pregnancy.

Evidence across different obstetric populations is consistent that increased pre-pregnancy BMI associates with increased obstetric interventions such as labour induction and surgical interventions. ${ }^{[8,9]}$ In support of these reports, Table 1 results showed that intranatal problems such as induction and caesarean section were more likely in the obese group. Increase in the risk of caesarean section rate after induction was independent of obstetric complications and confounding factors. One hypothesis for increased risk of caesarean section after induction includes altered uterine contractility combined with dysfunctional labour. Furthermore, priming the myometrium for transitioning from quiescence to contractility may be altered with increased BMI and adipose tissue mass.[10]

\begin{tabular}{|c|c|c|c|}
\hline & $\begin{array}{c}\text { Obese N=684 } \\
\text { (\%) }\end{array}$ & $\begin{array}{c}\text { Underweight } \\
\mathbf{N = 8 1 6}(\mathbf{\%})\end{array}$ & P value \\
\hline Pre-term & $126(18.42)$ & $117(14.33)$ & 0.0296 \\
\hline Term & $368(53.80)$ & $556(68.13)$ & 0.00001 \\
\hline Post-term & $190(27.77)$ & $143(17.52)$ & 0.0026 \\
\hline
\end{tabular}

Table 4. Comparison of Time of Delivery between the Two Groups

$\mathrm{P}_{1}$ comparison between weight gain below the normal recommended range and within the recommended range.

$\mathrm{P}_{2}$ comparison between weight gain above the normal recommended range and within the recommended range.

After adjusting for all confounding factors, we found positive association of BMI with GDM, pre-eclampsia, GHTN and APH (Table 2). Nan Li et al[11] and other previous studies concluded that obesity is associated with adverse pregnancy outcomes such as GDM and pregnancy-induced hypertension.

Consistent with the previous results, we found significantly high incidence of still birth with high BMI. Single most common modifiable factor for still birth in developed world is maternal obesity.[12] According to Auckland Prospective Stillbirth Study, ${ }^{[13]}$ obesity is an independent risk factor.

We found a significant correlation of obese women with foetal weight. The same has been shown in other study. Maternal obesity is a strong predictor of foetal birth weight or large for gestational age.[14-17] Recently, Modi et al[18] have shown that increasing maternal BMI is associated with the increasing abdominal and intrahepatocellular lipid content in neonatal offspring. It was observed that with the increase in abdominal circumference, neonatal morbidity increased.

We found significantly high proportion of mothers whose weight gain during pregnancy is above normal are with various complications in comparison to those mothers whose weight gain in pregnancy is normal or below normal except incidence of IUGR is high in mothers with low weight gain. There is positive association between gestational weight gain and GDM, macrosomia, GHTN and pre-eclampsia (Table 3). (Chi-square $=37.321, \mathrm{p}<0.001$ ). As data is categorical, Chisquare test is applicable. This association was consistent with the previous results.[11]

Table 4 showed that incidences of preterm and post-term delivery, both are high in the obese group. However, data supporting the preterm delivery in obesity are less conclusive.[19-21] A recent meta-analysis provided evidence that the association between preterm birth and obesity may vary depending upon the subtype of preterm births. ${ }^{[22]}$ Obesity and excess weight gain are associated with preterm birth, macrosomia and stillbirth, while underweight BMI and low weight gain have been associated with small for gestation or IUGR and preterm births.

Among studies related to risk factors for PPH, BMI is rarely considered as a risk factor for PPH. In these studies, results are inconsistent with the one showing no association of BMI with $\mathrm{PPH},[23]$ but others showing positive association.[24] Our study is very much similar with study done by Agarwal S et al and Ray JG.[23,25] 
There is a direct impact of high or low BMI on hospital admission and short-term costs to the health services.

\section{CONCLUSION}

In our study, we observed that both groups correlated well with various adverse foetomaternal outcomes. Apart from deleterious impact on pregnancy, obesity may also affect clinical decision for the management of labour and delivery, which ultimately may have repercussion on health care cost and maternity services. Thus, not only the antenatal period, but the intranatal as well as the postnatal period may be adversely affected in relation to BMI.

There is lack of studies on underweight pregnant women. Our study shows its association with anaemia only. Given a choice, obesity is more commonly associated with worse foetomaternal outcome. Weight is a very simple parameter, which can be easily measured. So, weight gain during pregnancy is an important clinical parameter to be followed. Identifying an obese or an underweight pregnant woman allows a proper planning throughout the antenatal period for any risk management. So referral to a dietician for dietary assessment and counselling should be considered for both lean and obese women.[26]

\section{Compliance with Ethical Requirements and Conflict of Interests}

We declare that we have no conflict of interest. As this was prospective observational study, not an interventional or case control study, informed consent with human subjects for being included in the study was not necessary; however, all procedures followed were in accordance with ethical standard of the responsible committee on human experiments (Institutional and National) and with the Helsinki Declaration of 1975 as revised in 2008 (5).

\section{ACKNOWLEDGEMENT}

We thank Medical Director, KIMSDU, Karad and head of our department for allowing us to use and publish the data related to patient.

\section{REFERENCES}

[1] WHO. Global InfoBase - data and analysis of overweight and obesity. Fact sheet $\mathrm{N}^{0} 311$, updated on January 2015.

[2] Reddy MN, Ch Kumar K, Jamil K. New world syndrome (obesity) in South India. Open Access Scientific Reports 2012;1(12):1-3. doi:10.4172/scientificreport.567.

[3] National Family Health Survey on Adult Nutrition. 2005-2006. Ministry of Health and Family Welfare, Government of India.

[4] Ahmed SR, Ellah MAA, Mohamed OA, et al. Prepregnancy obesity and pregnancy outcome. Int J Health Sci (Qassim) 2009;3(2):203-8.

[5] Institute of Medicine. Weight gain during pregnancy: re-examining the guidelines. Washington, DC: National Academic Press 2009.

[6] Tsoi E, Shaikh H, Robinson S, et al. Obesity in pregnancy: a major healthcare issue. Postgrad Med J 2010;86(1020):617-23.
[7] Brydon S. Guideline for low body mass index (BMI) in antenatal women, Nottingham University Hospitals (NHS Trust). July 2015.

[8] Arrowsmith S, Wray S, Quenby S. Maternal obesity and labour complication following induction of labour in prolonged pregnancy. BJOG 2011;118(5):578-88.

[9] Briese V, Voigt M, Wisser J, et al. Risk of pregnancy and birth in obese primiparous women: an analysis of German perinatal statistics. Arch Gynecol Obstet 2011;283(2):249-53.

[10] Lowe NK, Corwin EJ. Proposed biological linkage between obesity, stress and inefficient uterine contractility during labour in human. Med Hypothesis 2011;76(5):755-60.

[11] Li N, Liu E, Guo J, et al. Maternal pre-pregnancy body mass index and gestational weight gain on pregnancy outcome. PLoS One 2013;8(12):e82310.

[12] Flenady V, Middleton P, Smith GC, et al. Stillbirth: the way forward in high income countries. Lancet 2011;377(9778):1703-17.

[13] Stacey T, Thompson JM, Mitchell EA, et al. The Auckland Stillbirth study, a case control study exploring modifiable risk factors for third trimester stillbirth: methods and rationale. Aust $\mathrm{N} \mathrm{Z} \mathrm{J} \mathrm{Obstet}$ Gynecol 2011;51(1):3-8. Article first published online 6 Dec 2010.

[14] Makgoba M, Savvidou MD, Steer PJ. The effect of maternal characteristics and gestational diabetes on birth weight. BJOG 2012;119(9):1091-7.

[15] Voigt M, Zels K, Guthmann F, et al. Somatic classification of neonates based on birth weight, length and head circumference: quantification of the effect of maternal BMI and smoking. J Perinat Med 2011;39(3):291-7.

[16] Ovesen P, Rasmussen S, Kesmodel U. Effect of prepregnancy maternal overweight and obesity on pregnancy outcome. Obstet Gynecol 2011;118(2 Pt 1):305-12.

[17] Owens LA, O'Sullivan EP, Kirwan B, et al. ATLANTIC DIP: the impact of obesity on pregnancy outcome in glucose-tolerant women. Diabetes Care 2010;33(3):577-9.

[18] Modi N, Murgasova D, Ruager-Martin R, et al. The influence of maternal body mass index on infant adiposity and hepatic lipid content. Paediatr Res 2011;70(3):287-91.

[19] McDonald SD, Han Z, Mulla S, et al. Overweight and obesity in mothers and risk of preterm birth and low birth weight infants: systematic review and metaanalysis. BMJ 2010;341:c3428.

[20] Savitz DA, Stein CR, Siega-Riz AM, et al. Gestational weight gain and birth outcome in relation to prepregnancy body mass index and ethnicity. Ann Epidemiol 2011;21(2):78-85.

[21] Aly H, Hammad T, Nada A, et al. Maternal obesity, associated complications and risk of prematurity. J Perinatol 2010;30(7):447-51.

[22] Torloni MR, Betran AP, Daher S, et al. Maternal BMI and preterm birth: a systematic review of literature with meta-analysis. J Matern Fetal Neonatal Med 2009;22(11):957-70. 
[23] Agarwal S, Singh A. Obesity or underweight - What is worse in pregnancy? Journal of Obstet and Gynaecol India 2016;66(6):448-52.

[24] Lederman SA. Pregnancy weight gain and postpartum loss: avoiding obesity while optimizing the growth and development of the fetus. J Am Med Womens Assoc (1972) 2001;56(2):53-8.
[25] Ray JG, Vermeulen MJ, Shapiro JL, et al. Maternal and neonatal outcomes in pre-gestational and gestational diabetes mellitus and the influence of maternal obesity and weight gain: the DEPOSIT study. Diabetes Endocrine Pregnancy Outcome Study in Toronto. Q J Med 2001;94(7):347-56.

[26] Acker DB, Sachs BP, Friedman EA. Risk factors for shoulder dystocia. Obstet Gynecol 1985;66(6):762-8. 